\title{
The Effectiveness of Incorporating Technology in the Classroom as an Attractive Tool to Teach the Clothing and Textile Curriculum and the Concept of Sustainability
}

\author{
Nasim Idris Muhammad, Maha Abdullah Al Dabbagh \\ King Abdulaziz University, Jeddah, Makkah, KSA \\ Email: nmohammedaljalili@stu.kau.edu, Maldabag@kau.edu.sa
}

How to cite this paper: Muhammad, N. I., \& Al Dabbagh, M. A. (2021). The Effectiveness of Incorporating Technology in the Classroom as an Attractive Tool to Teach the Clothing and Textile Curriculum and the Concept of Sustainability. Open Journal of Social Sciences, 9, 279-292.

https://doi.org/10.4236/jss.2021.92019

Received: December 14, 2020

Accepted: February 17, 2021

Published: February 20, 2021

Copyright $\odot 2021$ by author(s) and Scientific Research Publishing Inc. This work is licensed under the Creative Commons Attribution International License (CC BY 4.0).

http://creativecommons.org/licenses/by/4.0/

\begin{abstract}
Extensive inclusion of technology in education has been one of the most promising recent advancements. Technology has radically changed the method of learning and teaching. Many studies have indicated that use of technology can increase students' interest in learning, and that use of technology in education has made teaching and learning more enjoyable tasks. In this respect, the present paper examines teachers' views about the incorporation of technology into educational environments, being a tool of attraction. It investigates the effectiveness of using technology as teaching tool within classrooms and seeks to examine whether or not the incorporation of technology as a teaching method affects the students' interest in the clothing and textile subject. It also highlights the importance of incorporating the concept of sustainability into the clothing and textile curriculum. In order to answers the research questions directed in line with the overall purpose of the study, the qualitative research method was applied. The research's findings have shown positive opinions and attitudes of experts and specialists on the use of technological tools as a teaching aid and an attractive tool to teach the educational curriculum of the textile and clothing section. This was confirmed by the questionnaire's results which have shown a tendency and preferences of teachers towards the use of technological tools as a teaching aid and an attractive tool to teach the educational curriculum of the textile and clothing section.
\end{abstract}

\section{Keywords}

Integration of Technology, Clothing and Textile Curriculum, Education for Sustainability, E-Learning 


\section{Introduction}

We have come to live in an era of scientific progress and technology and information revolution, where the exchange of information and expertise has become a hallmark of our time. Education in general had to face and keep pace with these rapid changes and developments.

Therefore, many important inspiring technological innovations have appeared to augment these developments and contribute to solving many educational problems. One of these technological innovations is e-learning, which provides interactive content based on interactive multimedia (Al-Sayed, 2018).

In the framework of the exerted efforts to develop education, the objectives of Saudi transformation program strategy, which was launched at the beginning of 2016, with the participation of the Ministry of Education along with other sectors in the Kingdom of Saudi Arabia, have focused on improving creativity and innovation-stimulating educational environment, and developing methods of education and rectification. These goals are linked to Vision 2030 that emphasizes the need to develop and utilize youth skills and empower them with the necessary life skills and knowledge that would enable them to cope with the needs of the future labor market.

Coping with this great technical progress, the educational strategies of the educational institutions have been developed, and employment of available technology has become a necessity for the education development process to be more effective in improving educational outcomes in a way that suits the needs of the twenty-first century's learners, and help increase their learning through serious and enjoyable learning at the same time (Hanan, 2019).

With today's world heading towards sustainability in all different aspects of life to improve the quality of life and preserve the environment, and as the fashion industry is considered the second largest polluting industry after oil, it was necessary to spread awareness of sustainability among our sons and daughters, and integrate this principle as life skills in the curricula of public schools and universities.

International calls for sustainability education over the past three decades have motivated various states and countries to integrate education of sustainability into educational programs and curricula (UNESCO, 2005).

New ways of thinking are needed in order to transform our education system and our society (Orr, 2004). Students need to understand complex problems facing our society today and be prepared to design and enact creative solutions. They also must be more aware of how their individual and collective actions impact the natural systems around us. Sustainability literate individuals have the ability and dispositions to solve problems, make decisions, and take appropriate actions that promote sustainability (Nolet, 2015).

The subject of clothing and textile is considered one of the subjects that integrates many life skills into one curriculum where students learn clothing, textile, arts, beauty, personal skills education and self-development. These skills 
help female students to become more capable people in dealing with life and its requirements. The Clothing Care study unit within the Family Education curriculum includes guidelines into how to preserve clothes by implementing different types of fabric care methods. Therefore, and given the importance of teaching such a curriculum, the researcher emphasizes the benefits of using technology as a teaching aid that would increase the students' interest in the subject, make the learning process more enjoyable and consequently, results in more well-informed students.

\section{Research Methodology}

Research can be carried out using different approaches, depending on the nature and aim the research. In the present study, which was carried out to reveal the views of elementary school teachers and field teachers about effective use and integration of technology in class environment and to determine the problems they experience in the process, a qualitative research method was applied. In this respect, a questionnaire was conducted and the data obtained were analyzed.

\section{Research Questions}

- Does the incorporation of technology as a teaching tool positively affect the students' interest in the clothing and textile subject?

- What is the effectiveness of incorporating the concept of sustainability into the clothing and textile curriculum?

\section{Research Objectives}

- Demonstrate the importance of using technology as teaching aid in the clothing and textile section.

- Highlight the importance of incorporating the concept of sustainability into the clothing and textile curriculum.

\section{Research Significance}

- It highlights the role technology can play in making learning more enjoyable as well as the importance of incorporating the concept of sustainability into the clothing and textile curriculum.

\section{Literature Review}

The following literature review demonstrates the value of using technology in making the educational process more enjoyable as well the impact of Education of Sustainability on Students.

\subsection{Benefits of Integration of Technology in Education}

The application of technologies in education is changing learners' experiences both inside and beyond the classrooms. The benefit of using technology in education has been well-researched. Mobile devices facilitate the connection be- 
tween tutors and learners to use computing capabilities anywhere. The internet and wireless technology promote interlink amidst mobile gadgets with other computing devices such as computers, tablets, and other items (Hinostroza et al., 2016). In her study, Wijdan Al-Shammari (2019), has examined the impact of contemporary technology on education in the Faculties of Fine Arts, and referred to the new vision brough by tablets and graphic tools. Al-Shammari used the experimental method for her research sample, which consisted of 32 male and female students. The results have indicated that the use of tablet computers and graphic tools in arts in general are important variables in the technical manifestations of electronic forms. This has established an integrated system that displaced the historical values of plastic arts and their associated tools by virtual brushes, colors, tools and effects that have been brought by computer software, thus enabling learners to produce various characteristics.

Ottenbreit-Leftwich and others (2010) stated that the use of technology in education is important to motivate student learning. Goldin and Katz (2018) researched on three factors that increase students' motivation in the technologically enhanced setting. The factors included communication, learning, and empowerment as students appreciated how they interact with others in real time by using technologies such as computers. Connecting with others is made possible by the internet enabling real-time communication. The learners were empowered in a technology surrounding, as they were secluded from teachers and were less scared of relating to others. Learners believed that computer enables them to have control over their learning by promoting independence (Goldin \& Katz, 2018).

The existence of technologies in the class set up learning has been effective particularly in ensuring the improvement of in-service teacher education and preparation for pre-service instructors to make sure successful alignment of educational technology in the learning activities. Recently teacher-learning establishment is making an effort to prepare for pre-service tutors to make sure there is an integration of technology into the future teaching practices (Anderson, 2016).

Ereiter and others (2006) maintained that integration of technology can help students improve several general skills such as problem solving and self-regulation or ICT skills. Hew et al. (2007) and Hennessy et al. (2005) maintained that technology integration has found about how teachers use technology to convey familiar activities more reliably and productively.

Other studies have shown that "there is an evolving relationship between education and technology, and the evolving pedagogies have also taken advantage of newly designed or emerging technologies. Diane and Steven (2007), stated that ubiquitous computing is being used for education and training to provide "augmented reality" interfaces, which are characterized by the use of handheld computers to infuse the virtual world onto the real one, resulting in deeply immersive simulations. Oliveira et al., (2019) carried out a review literature on emer- 
gent technologies from the field of science education. She maintains that technological artifacts such as computer simulations, virtual labs, mobile devices, robots, games, and digital photography and drawing are increasing the experience of learners. A study by Berland and Wilensky (2015) comparing the effectiveness of curricular units in supporting students' complex systems and computational thinking has shown that "students using the physical system were more likely to interpret situations from a bottom-up ("agent") perspective, and students using the virtual system were more likely to employ a top-down ("aggregate") perspective.

\subsection{Education and Sustainable Development}

The concept of sustainable development emerged as a response to a growing concern about human society's impact on the natural environment. The most common definition of sustainable development used is the one put forward in the Brundtland report: 'Sustainable development is development that meets the needs of the present without compromising the ability of future generations to meet their own needs' (Brundtland 1987). This definition acknowledges that while development may be necessary to meet human needs and improve the quality of life, it must happen without depleting the capacity of the natural environment to meet present and future needs. Teaching our students about sustainability is one of the most important things we can do to protect the future of humanity and the planet we live in. Creating a sustainable future seems to be one of the biggest challenges facing humanity. This challenge is further enhanced by ignorance of people toward the concept of sustainability. Students who are our future generation are left without any knowledge or even understanding their role and responsibility toward sustainability. Therefore, sustainability education is becoming crucial, mainly for young generation so that they have an understanding of concepts such as economic prosperity, resource equity, energy uses, and environmental health and concerns. While sustainability education begins in schools, it is important that sustainability education is well entrenched in the educational curriculum and everyday practice of their lives.

\subsection{Education for Sustainability}

Many schoolers have provided well-versed definition of the Education for Sustainability (EfS). Among these various available definitions for Education for Sustainability (EfS) the Australian Curriculum, Assessment and Reporting Authority (ACARA), has come up with a broad and inclusive definition and description that clearly illustrate the true meaning of Efs. As per ACAEA, "Education for sustainability develops the knowledge, skills, values and world-views necessary for people to act in ways that contribute to more sustainable patterns of living. It enables individuals and communities to reflect on ways of interpreting and engaging with the world. Sustainability education is futures-oriented, focusing on protecting environments and creating a more ecologically and so- 
cially just world through informed action.

Education for Sustainability (EfS) is "an educational approach that aims to develop students, schools and communities with the values and the motivation to take action for sustainability in their personal lives, within their community and also at a global scale, now and in the future. It aims to build awareness and knowledge of sustainability issues but also to develop students and schools that are able to think critically, innovate and provide solutions towards more sustainable patterns of living.

\subsection{EfS Effect on Students}

Several studies have investigated the impact of EfS Effect on Students. In his study "The Essential Elements of Education for Sustainability (EfS): Editorial Introduction from the Guest Editor", Jaimie Cloud JSE May 2014 has listed nine effects of Efs as follows: improves student learning; an enhances attitudes towards learning; Improves student learning and standards achievement; enhances attitudes towards learning; produces better behavior and attendance; aligns with people's natural ability to learn holistically; significantly decreases students' feeling that they cannot succeed; encourages students to make connections between themselves and the systems of which they are a part; develops a greater awareness of community, and a greater appreciation of the democratic process; produces statistically significant increases in the strength of students' attitudes about civic engagement; provides a safe and secure space in which children can take risks and develop skills of active participation (Jaimie Cloud, 2014).

People are the true wealth of any nation. Adequately prepared and well educated, they can push a country towards development and prosperity. With this in mind, the Saudi Arabian government has always believed that developing the nation's citizens is not only an investment but a sacred duty too. Therefore, since its establishment, it has embarked on a huge mission to nourish and preserve the spiritual, moral, cultural, intellectual, and physical development of its citizens. The government has, since 1932, established free education, training, and health institutions all over the country.

\subsection{Education for Sustainability in the Kingdome of Saudi Arabia}

Saudi Arabia pays considerable attention to basic services which respond to the needs of the population, with education in the forefront of these needs. Education accounts for the largest share of the 2018 state budget allocation. A total of USD 51 billion (SAR 192 billion) has been earmarked for general education, higher education and training sector. In fact, the education sector receives direct support and follow-up from the Custodian of the Two Holy Mosques, King Salman bin Abdulaziz and the Crown Prince, HRH Prince Mohammad bin Salman. Both play a leading role in accelerating the Kingdom's development process which will place Saudi Arabia at the forefront of technologically advanced na- 
tions (UN, 2018). Therefore, the Ministry of Education seeks to provide education opportunities for all within an adequate education environment, in the light of the Kingdom's education policy. The Ministry also seeks to raise the quality of output and to increase the efficiency of scientific research. The Vision 2030 education component addresses three key areas: development of curricula, advancement of higher education and building of skills that are necessary for the labor market. Saudi Arabia embarked on a process to align its national strategies in various sectors with the SDGs. The Ministry of Environment, Water and Agriculture (MEWA), for example, issued the Water Strategy and the Environment Strategy, which are aligned with The SDGs, with sufficient integration of social, economic and environmental dimensions. As the Kingdom of Saudi Arabia consistently accords due attention to education as a key driver to advance development, a Royal Order was issued to include the SDGs into education curricula. Work is in progress towards this end, led by the Ministry of Education, in partnership with public and private stakeholders. Furthermore, work is underway to develop more strategies and plans, which are designed to promote national frameworks' coverage of the SDGs.

\subsection{The Importance of Incorporating Sustainability in the Fashion and Textile Curriculum}

In the past few years, sustainable design has gained more and more importance. Our clothing consumption has reached an all-time high, and in response, advocates for mindful, eco-friendlier design are screaming their message louder than ever. In textile and fashion field, one of the factors permitting to enhance this new tendency and need is to incorporate into the fashion and textile curriculum the value of eco-design and sustainability, especially for textile and fashion students to respond to the Principles for Responsible Management Education (PRME) of the United Nations Global by incorporating the concept of environmental responsibility into the education that will play a key role in the evolution of society towards sustainability (Tilbury, 2004). The education space is one of the greatest places to initiate and develop the changes that we need in the world. Education for sustainability applied to textile and fashion. In this context, some researchers introduce new forms of learning which lead to sustainable lifestyle behavioural changes among participants such as Otte, (Otte, 2016) which introduces a course concept called "Experts in Teams" (EiT) as a new platform of learning which makes use of experience-based learning to address sustainable development in an academic context. Another educational experience is the sustainable campus project of National Taiwan Normal University has been an environmental education platform for both formal and non-formal education. This project demonstrates how to actualize the concept of sustainability in our surrounding environment by strengthening participation of local teachers and pupils in curriculum-centered environmental learning and change processes (Chang \& Chou, 2005). 


\section{Questionnaire Design and Results}

Aquestionnaire was designed and distributed to 30 teachers of the Family Education section to measure the importance of incorporating technology in classroom, as well as the importance of teaching students the concept of sustainability. The results were as follows (Figures 1-9):

What is the effect of sustainability based curriculum on students' acquisition of some life skills that contribute to the concept of sustainability?

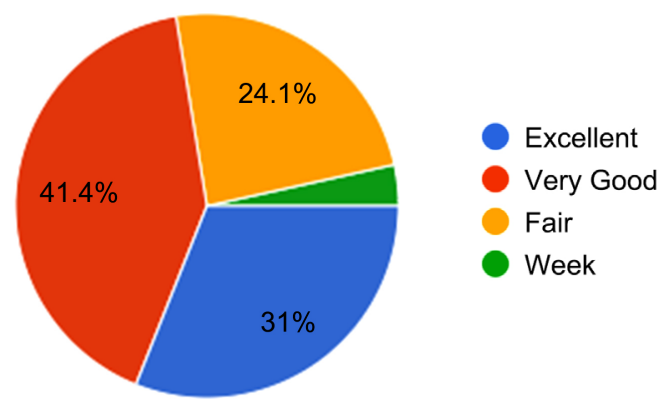

Figure $1.41 \%$ of the teachers said the effect is excellent, $31 \%$ said the effect is very good, $24 \%$ said the effect is fair.

Does the incorporation of technology as a teaching method positively affect the students' interest in the clothing and textile subject?

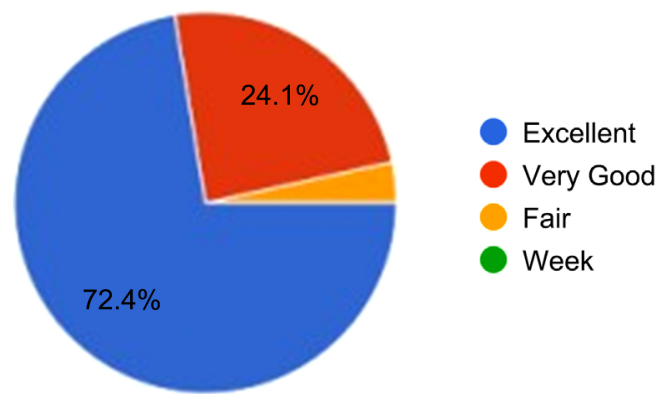

Figure 2. 72\% of the teachers said they strongly agree, while $24 \%$ said they relatively agree.

Does the incorporation of technology in fashion and textiles section increase students' understanding of the subject?

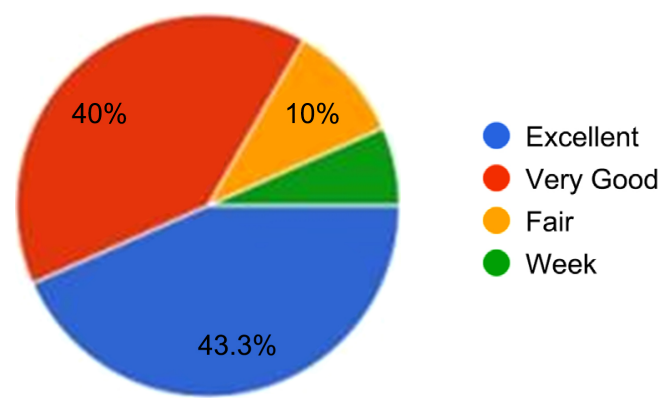

Figure 3. $43 \%$ of the teachers said they strongly agree, while $40 \%$ said they relatively agree. 
In your point of view as a teacher, do you think students have an idea about the concept of sustainability?

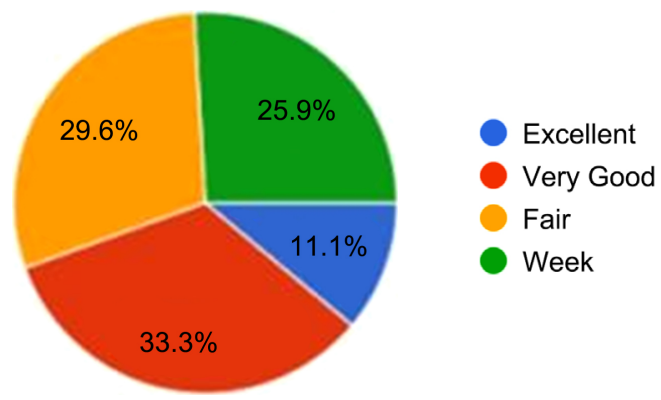

Figure $4.33 \%$ of the teachers said they relatively agree that their students have some know-ledge on the concept of sustainability, while $25 \%$ said they don't think so.

Do you think that conducting technology-based activities inside the classroom will be helpful in teaching life skills such as recycling materials?

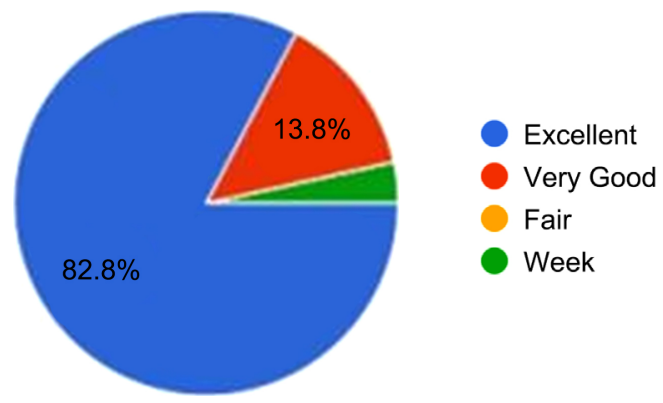

Figure $5.82 \%$ of the teachers said they strongly agree, while $13 \%$ said they relatively agree.

Do you think students' awareness of the concept of clothing sustainability will be increased after implementing a technology-based teaching strategy?

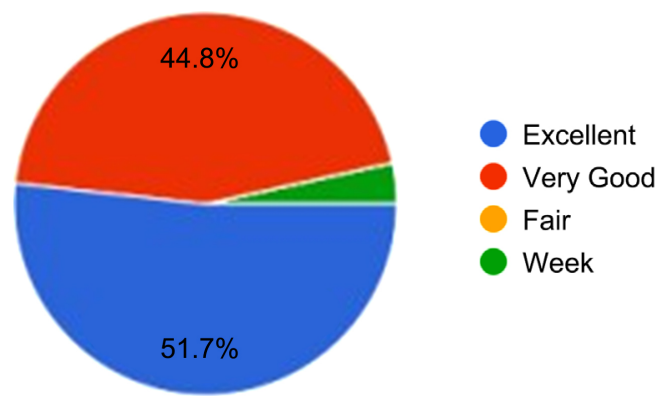

Figure $6.51 \%$ of the teachers said they strongly agree, while $44 \%$ said they relatively agree.

Do you think students will be able to repair their clothing themselves and keep them for longer time after implementing a technology-based teaching strategy? 


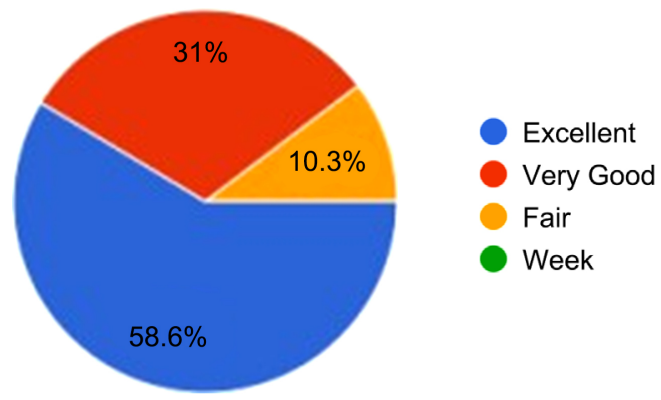

Figure $7.58 \%$ of the teachers said they strongly agree, while $31 \%$ said they relatively agree.

Do you think students will be able to find ways to reuse and recycle their clothing instead of discarding them with the aid of a technology-based teaching strategy?

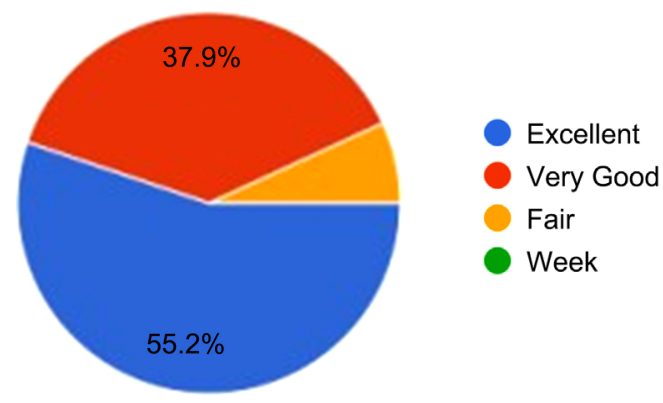

Figure $8.55 \%$ of the teachers said they strongly agree, while $37 \%$ said they relatively agree.

Do you think students will be able to distinguish between the different clothing care methods according to the type of textile (Cotton, Linen, Silk, Wool), with the aid of a technology-based teaching strategy?

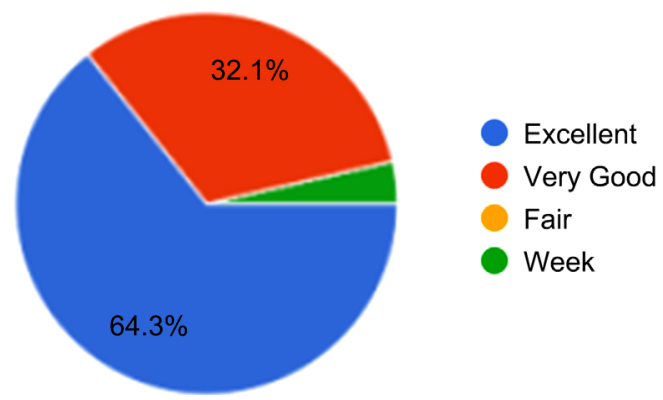

Figure 9. $64 \%$ of the teachers said they strongly agree, while $32 \%$ said they relatively agree.

\section{Discussion of Results and Conclusion}

The overall results driven from this questionnaire show a tendency and preferences towards the use of technological tools as a teaching aid as well as teaching of sustainability in the educational curriculum of the textile and clothing section. 
Various researches have highlighted the values associated with the use of technological tools as a method of teaching in classrooms. Moreover, the idea of incorporating the concept of sustainability into the clothing and textile curriculum was vehemently accentuated by many studies.

Regarding the effect of sustainability-based curriculum on students' acquisition of some life skills that contribute to the concept of sustainability, a majority of teachers (41\%) said the effect is excellent, $31 \%$ said the effect is very good, and $24 \%$ said the effect is fair. This demonstrates the importance of incorporating the concept of sustainability in the curriculum to help students acquire some life skills that would contribute to the fulfillment of the concept of sustainability.

When asked whether the incorporation of technology in classroom positively affects the students' interest in the clothing and textile subject, most teachers (72\%) said they strongly agree, while $24 \%$ said they relatively agree. This answers the research's question on whether the incorporation of technology as a teaching tool increases the students' interest in the subject. When asked whether the incorporation of technology in teaching the clothing and textile subject increases students' understanding of the subject, $43 \%$ of the teachers said they strongly agree, while $40 \%$ said they relatively agree. This indicates that a good percentage of teachers are not aware of the value of technology as a teaching tool and need to be educated on how technology can boost students' understanding.

When asked whether students have some ideas about the concept of sustainability, $33 \%$ of the teachers said they relatively agree that their students have some knowledge on the concept of sustainability, while $25 \%$ said they don't think so, $29.6 \%$ said they don't know and $11.1 \%$ said no. This is indicative of the need to focus on increasing teaching of sustainability in classrooms. Regarding their opinion on the use of technology-based activities inside the classroom to teach students life skills, such as recycling materials and clothes instead of discarding them, a majority of teachers (82\%) said they strongly support the idea, while $13 \%$ said they relatively do. This also answers the research's question regarding the effectiveness of incorporating technology as a teaching tool in classrooms. The researcher also included some questions that have demonstrated the value a technology-based teaching strategy can offer if applied within classroom as follow: Responding to a question on whether students' awareness of the concept of clothing sustainability will be increased after implementing a technology-based teaching strategy, $51 \%$ of the teachers said they strongly agree, while $44 \%$ said they relatively agree. Responding to a question whether students will be able to repair their clothes and keep them longer time with the aid of a technology-based teaching strategy, $58 \%$ of the teachers said they strongly agree, while $31 \%$ said they relatively agree. Asked whether students will be able to find ways to reuse and recycle their clothing instead of discarding with the aid of a technology-based teaching strategy, $55 \%$ of the teachers said they strongly agree, while $37 \%$ said they relatively agree. Regarding their opinion on whether students will be able to use the applique technique in beautifying damaged fabrics 
instead of discarding them after implementing a technology-based teaching strategy, $53 \%$ of the teachers said they strongly agree that their students will be able to do so, 35\% said they relatively agree, and 7\% said they do not agree. Regarding their opinion whether students will be able to distinguish between the different methods of caring for fabrics according to its type (cotton, linen, silk, wool), with the aid of a technology-based teaching strategy, $64 \%$ of the teachers said they strongly agree, while $32 \%$ said they relatively agree.

The results highlight the necessity to use technology in classroom and agree with many studies that have shown the effectiveness of use of technology in classrooms. Additionally, the questionnaire's results have highlighted the need to introduce the concept of sustainability as a part of the clothing and textile curriculum. It also stressed the importance to encourage students to adopt the concept of sustainability in various aspects of life.

As demonstrated by the findings obtained in the present study, teachers are willing to use technology in their courses. The researcher has made several recommendations including offering the research's results to researchers for more manipulation; taking into account the importance of employing computers in the education process; highlighting the importance of adopting the tablet and graphics computers as an effective building unit for plastic work.

\section{The Research Recommendations}

To further enhance significance of this study, the researcher has come up with some recommendations as follows:

- Utilizing the use of technology in the preparation of the scientific curriculum in order to produce an easy and interesting educational material which would increase the students' interest in and understanding of the clothing and textile subject.

- Incorporating the concept of sustainability in the educational curricula, and raise the students' awareness on its importance of preserving the environment in the present or in the future.

- Holding courses and activities that would enrich the concept of sustainability, and providing training courses for femalelmale students, employees and housewives on how to reuse or recycle waste materials instead of discarding them.

\section{Future studies}

In order to supplement the efforts made in this study, the researcher proposes to conduct the following study:

- The possibility of incorporating the concepts of sustainable development in the educational curricula of schools and universities.

\section{Conflicts of Interest}

The authors declare no conflicts of interest regarding the publication of this paper. 


\section{References}

Al-Sayed, H. (2018). Effectiveness of Using e-Blended Learning, Learner-Centered Teaching Strategies According to the FARC Model on Learning Outcomes and Motivation. College of Education (Part 2).

Al-Shammari, W. (2019). Using e-Learning to Enrich the Aesthetic Experience of Students of the College of Beautiful Arts. Arab Journal of Educational and Psychological Sciences, 7 .

Anderson, T. (2016). Theories for Learning with Emerging Technologies. In G. Veletsianos (Ed.), Emergence and Innovation in Digital Learning: Foundations and Applications (pp. 35-50). Edmonton: Athabasca University Press.

Berland, M., \& Wilensky, U. (2015). Comparing Virtual and Physical Robotics Environments for Supporting Complex Systems and Computational Thinking. Journal of Science Education and Technology, 24, 628-647.

https://doi.org/10.1007/s10956-015-9552-x

Brundtland, G. (1987). Our Common Future: The World Commission on Environment and Development. Oxford: Oxford University Press.

Chang, T. C., \& Chou, J. (2005). National Taiwan Normal University's Efforts on Establishing a Sustainable Campus: A Situational Report to the UNESC O Chair in Reorienting Teacher Education towards Sustainability.

Cloud, J. (2014). The Essential Elements of Education for Sustainability (EfS): Editorial Introduction from the Guest Editor.

Diane, J. K., \& Steven, M. N. (2007). Emerging Technologies in Education and Training: Applications for the Laboratory Animal Science Community. ILAR Journal, 48, 163-169. https://doi.org/10.1093/ilar.48.2.163

Ereiter, C., \& Scardamalia, M. (2006). Education for the Knowledge Age: Design-Centered Models of Teaching and Instruction. In P. A. Alexander, \& P. H. Winne (Eds.), Handbook of Educational Psychology (2nd ed., pp. 695-713). Mahwah, NJ: Erlbaum.

Goldin, C., \& Katz, L. F. (2018). The Race between Education and Technology. In Inequality in the 21st Century (pp. 49-54). London: Routledge. https://doi.org/10.4324/9780429499821-10

Hanan (2019). The Effectiveness of a Proposed Program to Develop Gamification Design Skills and Employment among Female Students. Diploma in Electronic Education and Their Perceptions of It.

Hennessy, S., Ruthven, K., \& Brindley, S. (2005). Teacher Perspectives on Integrating ICT into Subject Teaching: Commitment, Constraints, Caution, and Change. Journal of Curriculum Studies, 37, 155-192. https://doi.org/10.1080/0022027032000276961

Hew, K. F., \& Brush, T. H. (2007). Integrating Technology into K-12 Teaching and Learning: Current Knowledge Gaps and Recommendations for Future Research. Educational Technology Research and Development, 55, 223-252.

https://doi.org/10.1007/s11423-006-9022-5

Hinostroza, J. E., Ibieta, A. I., Claro, M., \& Labbé, C. (2016). Characterisation of Teachers' Use of Computers and Internet inside and outside the Classroom: The Need to Focus on the Quality. Education and Information Technologies, 21, 1595-1610. https://doi.org/10.1007/s10639-015-9404-6

Nolet, V. (2015). Educating for Sustainability: Principles and Practices for Teachers. London: Routledge. https://doi.org/10.4324/9781315867052

Oliveira, A., Behnagh, R. F., Ni, L., Mohsinah, A. A., Burgess, K. J., \& Guo, L. (2019). 
Emerging Technologies as Pedagogical Tools for Teaching and Learning Science: A Literature Review. Human Behavior and Emerging Technologies, 1, 149-160.

https://doi.org/10.1002/hbe2.141

Orr, D. W. (2004). Earth in Mind: On Education, Environment, and the Human Prospect. Washington DC: Island Press.

Otte, P. P. (2016). Integrating Sustainable Development in Higher Education through Experience-Based Learning: Insights from Experts in Team (EiT) for Developing a Combined Theoretical Framework. Journal of Education for Sustainable Development, 10, 131-159. https://doi.org/10.1177/0973408215625550

Ottenbreit-Leftwich, A. T., Glazewskib, K. D., Newby, T. J., \& Ertmer, P. A. (2010). Teacher Value Beliefs Associated with Using Technology: Addressing Professional and Student Needs. Computers and Education, 55, 1321-1335.

https://doi.org/10.1016/j.compedu.2010.06.002

Tilbury, D. (2004). Environmental Education for Sustainability: A Force for Change in Higher Education. In P. B. Corcoran, \& A. E. J. Wals (Eds.), Higher Education and the Challenge of Sustainability (pp. 97-112). Dordrecht: Kluwer Academic Publishers. https://doi.org/10.1007/0-306-48515-X 9

UN (2018). Towards Saudi Arabia's Sustainable Tomorrow, First Voluntary National Review 2018-1439.

https://sustainabledevelopment.un.org/content/documents/20230SDGs English Repor t972018 FINAL.pdf

UNESCO (2005). United Nations Decade of Education for Sustainable Development 2005-2014. International Implementation Scheme.

http://unesdoc.unesco.org/images/0014/001486/148654e.pdf 